\title{
Does the gender composition of forest and fishery management groups affect resource governance and conservation outcomes: a systematic map protocol
}

Craig Leisher ${ }^{1 *}$, Gheda Temsah², Francesca Booker ${ }^{3,4}$, Michael Day $^{3,4}$, Bina Agarwal ${ }^{5}$, Elizabeth Matthews ${ }^{6}$, Dilys Roe ${ }^{4}$, Diane Russell ${ }^{7}$, Leah Samberg ${ }^{8}$, Terry Sunderland ${ }^{3}$ and David Wilkie ${ }^{6}$

\begin{abstract}
Background: In the fields of environmental governance and biodiversity conservation, there is a growing awareness that gender has an influence on resource use and management. Several studies argue that empowering women in resource governance can lead to beneficial outcomes for resource sustainability and biodiversity conservation. Yet how robust is the evidence to support this claim? Here we focus on the forestry and fisheries sectors to answer the primary question: What is the evidence that the gender composition of forest and fishery management groups affects resource governance and conservation outcomes? Our objective is to produce a systematic map of the evidence highlighting, inter alia, the geographic distribution and quality of the evidence, the consistency and robustness of the findings, and where further research is needed.

Methods/design: This protocol provides the details of the methodology. The search terms used to identify relevant articles were developed in an iterative process using the phraseology of the primary question, Boolean operators, and a list of synonyms for each term. The search terms will be used to identify relevant articles in CAB Abstracts, Scopus, AGRIS, AGRICOLA, Google Scholar, and Google. A test library of 12 articles will ensure that the search captures the relevant literature. Searches will be in English but will not be restricted by publication date. The websites of 22 international organisations with a known interest in gender-related issues will be screened for relevant documents. The gender-focussed researchers at large conservation NGOs, the members of the Poverty and Conservation Learning Group, and the members of the Gender and Environment Working Group will be invited to submit relevant documents. The list of references of included articles will be screened to identify other relevant articles in a 'backwards snowballing' approach. The inclusion criteria are that an article refers to women or gender, forests or fisheries, a resource management group, a quantitative comparison, and an environmental governance or biodiversity conservation outcome in a non-OECD country. A data extraction template with 27 variables will be used to assess the included articles. The output will be a narrative report with descriptive statistics and an evidence-gap map.
\end{abstract}

Keywords: Citizen participation, Conservation, Equity, Fishing, Forests, Gender impacts, Livelihoods, Sustainability

\footnotetext{
* Correspondence: craig.leisher@tnc.org

${ }^{1}$ The Nature Conservancy (TNC), 4245 North Fairfax Drive, Arlington, VA 22203, USA

Full list of author information is available at the end of the article
}

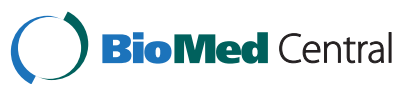

(C) 2015 Leisher et al.; licensee BioMed Central. This is an Open Access article distributed under the terms of the Creative Commons Attribution License (http://creativecommons.org/licenses/by/4.0), which permits unrestricted use, distribution, and reproduction in any medium, provided the original work is properly credited. The Creative Commons Public Domain Dedication waiver (http://creativecommons.org/publicdomain/zero/1.0/) applies to the data made available in this article, unless otherwise stated. 


\section{Background}

A varied body of research suggests that a group's gender composition can significantly affect decision-making processes and their outcomes. For example, a company's financial performance tends to improve when both men and women are represented on a corporate board or management team [1,2]. Likewise, forest management committees with a higher proportion of women represented have a greater likelihood of improving forest conditions [3]. Collaboration, conflict resolution, and the capacity for self-sustaining collective action can increase when women are part of a natural resource management group [4]. Women's participation in a policy-making group can also lead to choices that promote particular public goods [5]; in rural India, for instance, female leaders on village councils were found to be more likely to invest in public goods such as drinking water facilities than male leaders [6,7]. There may also be a 'critical mass' of women-for instance, one quarter to one third of a group-that is required before women effectively participate in decisionmaking [8]. At the same time, data from forest-user groups in Uganda, Bolivia, Kenya and Mexico (although based on small country samples which preclude generalisation) suggests that too high a proportion of women may also be suboptimal in that pre-dominantly female groups may be disadvantaged [9]. In short, there is emerging evidence suggesting that the gender balance of decision-making groups influences outcomes.

Within natural resource governance, understanding the socioeconomic contexts and gender norms-the socially prescribed and differentiated roles, responsibilities, and rights of women and men-may help in determining optimal configurations for natural resource management groups. Yet the configurations could be context specific and the responses non-linear. Gender relations vary across cultures and historical periods and intersect with other axes of social stratification, such as race, caste, wealth, class, age, and sexual identity $[10,11]$.

In many of the world's most vulnerable and biologically diverse landscapes, women's access to, control over, and use of local natural resources often differs to that of men. For example, a gender-disaggregated study of forest dependence in 24 tropical countries found that, in some contexts, men tend to focus more on hunting and collecting building materials while women focus more on collecting edible and medicinal plants [12]. However, the same study found that gender roles determining the collection of forest products may also vary. Women and girls, for example, typically collect firewood in parts of Africa and Asia [3], although in some instances, both women and men can be found collecting firewood [12]. Differences in women and men's access to, control over, and use of local natural resources may shape the management of resources, and including both women and men in resource management institutions could lead to improved environmental governance and biodiversity conservation outcomes.

A growing understanding of the influence of gender on natural resource outcomes has led to greater attention to gender among conservation organizations (e.g., [13-16]). In 2013, The Nature Conservancy (TNC), Wildlife Conservation Society (WCS), US Agency for International Development (USAID), Center for International Forestry Research (CIFOR), and others developed a proposal to assess the contexts and processes conducive to 'gender integration' in conservation projects. Ultimately, the proposal was not funded because, among other issues, not enough robust evidence had been garnered of explicit gender-conservation links. This protocol is a first step towards addressing this shortfall, and will lead to a systematic map of the evidence of links between gender-conscious resource governance and biodiversity conservation outcomes.

The systematic map was conceptualized during meetings in Manchester, London, New York, and Washington DC. The organisational stakeholders are TNC, WCS, USAID, CIFOR, the International Institute for Environment and Development (IIED), and ICF International (ICFI). Bina Agarwal at the Universities of Manchester and Delhi is also a stakeholder, and it was her findings from India and Nepal on the resource governance benefits from women's inclusion in local forest management that led us to ask whether we might find similar results from other countries and contexts [3,5]. In mid-2012, a rapid review of the gender and conservation literature by TNC suggested that similar studies from other countries and contexts may be rare [17]. Hence, in this current review, the stakeholders elected to focus on a systematic mapping of the available evidence rather than a broader systematic review with data synthesis. The 2012 rapid review also found that the evidence for gender-conservation links appeared to be most prevalent in the forestry and fisheries sectors. These two sectors are also of particular interest to the organisational stakeholders.

The objective of this systematic map is to provide an overview of the existing evidence linking the gender balance of natural resource management groups to environmental governance and biodiversity conservation outcomes in forestry and fisheries and to identify areas for future research and active dissemination.

Our primary question is:

- What is the evidence that the gender composition of forest and fishery management groups affects resource governance and conservation outcomes?

The primary question was developed in an iterative process with the stakeholders and may be revised as the work progresses. 
The primary question has the following P.I.C.O. components:

Population: Forest and fisheries resource management groups in non-OECD countries.

Intervention: Including both women and men on natural resource management groups (mixed-gender management).

Comparator: Before-after mixed-gender management (temporal comparator), presence-absence mixed-gender management (spatial comparator), or both.

Outcome: All outcomes related to changes in governance, including equity of resource distribution, secure resource rights, empowerment of communities to manage community or state owned resources, and participation of citizens in decision making. All outcomes related to conservation efficacy, including-but not restricted to-improvements in forest cover, greater forest protection, greater abundance of non-timber forest products, reforestation, afforestation, more sustainable timber harvests, increased use of agroforestry, improved fishing regulations, more sustainable fish and invertebrate catches, and fish and invertebrate species diversity and biomass.

Herein, we define 'gender' as social constructs ascribing to women and men different abilities, attitudes, personality traits, and behaviour patterns as well as power and systems of differentiation that are revealed in the unequal division of labour and resources between women and men [11]. An article is deemed to include gender if it mentions gender-specific treatments, activities, or strategies.

'Forests' are defined as more than 0.5 hectares of land with trees higher than 5 meters and a canopy cover of more than $10 \%$, or trees able to reach these thresholds in situ. It does not include land that is predominantly under agricultural or urban land use [18]. A 'fishery' is the harvest of fish and/or invertebrates and includes both marine and freshwater areas. An article is deemed to focus on forestry or fisheries if it mentions these as the focal area.

A 'management group' is defined for the systematic map as an organized group of people who govern a forest or fishery resource.

'Governance' is defined as a process by which authority to regulate actions is conferred and the manner in which rules are made and applied. Good governance is associated with a number of factors: accountability; transparency; protection of rights; equal application of the law; responsiveness of governing institutions; efficient delivery of public services; social inclusion; and citizen participation [19-21].

'Biodiversity' is defined as per Article 2 of the Convention on Biological Diversity [22] and 'conservation' is defined as the preservation, protection, or restoration of biodiversity or natural resources. We will seek articles that mention an environmental governance or biodiversity conservation outcome, such as empowering a community to manage a local forest sustainability (governance) or maintaining or increasing forest cover (conservation).

We chose to focus on non-OECD countries because this is the focus of international development assistance. The gender gaps in non-OECD countries also tend to be larger than OECD countries [23], and thus gender differences in natural resource use may be greater and the outcomes from the gender composition of a resource management group may be more pronounced.

We chose to focus on quantitative studies primarily because of the growing interest in evidence-based conservation [24-26] but also because assessing the quality of qualitative studies may be more subjective and complex [27] and variability is to be expected given differences in researchers' perceptions and rapport with participants [28].

\section{Methods/design \\ Searches}

The search terms were tested in CABI's CAB Abstracts database [29] using the OvidSP platform [30] and Elsevier's Scopus [31]. The project team compiled an initial list of search terms broadly related to the research question's population (using synonyms of 'resource governance and conservation') and intervention (using synonyms of 'gender'). This list was developed iteratively and further terms were added as they were identified during the literature searches. For searches in CAB Abstracts, the CAB Thesaurus [32] was used to refine and add search terms.

The final search terms were selected based on the presence of publications from a test library of 12 relevant studies and on the number of search results they generated (see 'Additional file 1: Articles in the test library'). The proposed final iterations of the search strings are given in Table 1.

The following bibliographic databases will be searched for publications:

- CAB Abstracts

- Scopus

- AGRIS

- AGRICOLA

These databases were selected because CAB Abstract indexes publications from 150 countries and is among the more comprehensive title and abstract databases for applied life sciences and the environment. Scopus is the largest abstract and citation database of peer-reviewed literature. AGRIS [33] and AGRICOLA [34] are smaller bibliographic databases that often have unique holdings 
Table 1 Proposed search strings

\begin{tabular}{lll}
\hline & Search string & $\begin{array}{c}\text { Number of search } \\
\text { results }\end{array}$ \\
\hline CAB & $\begin{array}{l}\text { Forest OR Fisheries OR Forest management OR Fishery management OR community forestry OR resource } \\
\text { Abstracts } \\
\text { management OR forestry resources OR fishery resources AND Women OR Gender relations OR social } \\
\text { participation OR community involvement OR citizen participation OR participative management OR employee } \\
\text { participation OR participation OR decision making OR empowerment OR community action OR 'decision making' }\end{array}$ & 7,873 \\
Scopus & $\begin{array}{l}\text { (women* OR * gender* OR empower*) AND TITLE-ABS-KEY (fisher* OR forest* OR \{resource management\} OR } \\
\text { (natural resources\} or biodiversity or conservation OR marine) }\end{array}$ & $\begin{array}{l}\text { Approx. 5550 (with } \\
\text { duplicates removed) }\end{array}$ \\
\hline
\end{tabular}

relevant to the environment. (AGRIS and AGRICOLA use basic search strings and hence were no included in the search string development.) The scoping strategy is shown in more detail in 'Additional file 2: Scoping strategy used for bibliographic databases'.

Within each database, the results will be modified by Boolean operators, wildcards, and limited to relevant subject areas. Searches will be undertaken in English (due to constraints of time) and will not be restricted by publication date. Descriptions of the final searches conducted will be documented in full. Endnote [35] will be used to manage the full-text documents.
Google Scholar [36] will be searched using simple search terms such as 'gender AND resource management' due to limitations of advanced searching on this platform. The first 100 search results, when organised by relevance, will be reviewed. Searches will also be conducted in Google [37] using the same search terms. Again, the first 100 results, when ordered by relevance, will be reviewed.

Publications on gender and natural resources may be on the websites of various organisations, and we will search a number of websites (Table 2). This list of organisations comes primarily from a rapid gender review

Table 2 List of websites to be searched for non-academic sources

\begin{tabular}{|c|c|}
\hline Organisation & Website \\
\hline African Development Bank (AfDB) & www.afdb.org/en/ \\
\hline Asian Development Bank (ADB) & www.adb.org \\
\hline Australian Agency for International Development (AusAID) & http://aid.dfat.gov.au/Pages/home.aspx \\
\hline CARE International & www.care-international.org/ \\
\hline CARE US & www.care.org \\
\hline Center for International Forestry Research (CIFOR) & www.cifor.org \\
\hline Convention on Biological Diversity (CBD) & www.cbd.int \\
\hline Department for International Development (DFID) & $\begin{array}{l}\text { www.gov.uk/government/organisations/department-for-international- } \\
\text { development }\end{array}$ \\
\hline Food and Agriculture Organisation (FAO) & www.fao.org \\
\hline Inter-American Development Bank (IADB) & www.iadb.org \\
\hline International Food Policy Research Institute (IFPRI) & www.ifpri.org \\
\hline International Fund for Agricultural Development (IFAD) & www.ifad.org \\
\hline International Initiative for Impact Evaluation (3ie) & www.3ieimpact.org \\
\hline International Institute for Environment and Development (IIED) & www.iied.org \\
\hline International Union for Conservation of Nature (IUCN) & www.iucn.org \\
\hline Secretariat of the Pacific Community (SPC) & www.spc.int \\
\hline United Nations Environment Programme (UNEP) & www.unep.org \\
\hline United Nations Development Programme (UNDP) & www.undp.org \\
\hline United States Agency for International Development (USAID) & www.usaid.gov \\
\hline $\begin{array}{l}\text { Women Organizing for Change in Agriculture and Natural Resource } \\
\text { Management (WOCAN) }\end{array}$ & www.wocan.org \\
\hline World Bank & www.worldbank.org \\
\hline WorldFish & www.worldfishcenter.org \\
\hline
\end{tabular}


conducted in 2012 using Google to identify international organisations with resource documents on gender [17]. Searches on these websites will use similar search terms as in Google whenever the site allows.

Through a process of external engagement, expert input will be sought on additional relevant documents. We will invite the gender experts at large conservation organizations, the $1,000+$ members of the (an international network convened by IIED) and Conservation Learning Group [38], and the 40+ members of the Gender and Environment Working Group [39] to submit relevant documents and articles, adding those that meet the inclusion criteria but are not already in the search results. We will also use 'backwards snowballing' whereby references in an included article are screened for additional relevant articles that meet the inclusion criteria [40]. Finally, we will screen the bibliographies of relevant systematic reviews published by Environmental Evidence, Collaboration for Environmental Evidence, 3ie, and the Campbell Collaboration for potential articles.

Limitations to the comprehensiveness of the review include the English language focus, difficulties accessing known but not publically available literature, and limiting the website searches to the organisations listed above. There may also be inherent geographic and sector biases that lead to overrepresentation or under-representation of included studies.

\section{Article screening}

After the articles captured through the searches are compiled and duplicates removed, the inclusion criteria below will be used to identify relevant articles:

Relevant population(s): Refers to a forest or fisheries focus and a management group for the resource in a non-OECD country

Relevant exposure(s): Refers to women or gender in the context of a management group

Relevant comparator(s): Refers to a quantitative comparison of management groups

Relevant outcome(s): Refers to a resource governance or biodiversity conservation outcome

Relevant study design: All quantitative study designs will be included

The review will use a three-stage sequential screening process. It will assess the title first, the abstract second, and then the full text using the above inclusion criteria. When applying the inclusion criteria to the search results, documents will be assessed independently, with each reviewer assigned a portion of the literature. Where there is doubt about whether or not an article meets the inclusion criteria, it will be retained for assessment at the next stage. All final decisions on whether to include a document for which an individual reviewer is uncertain will be made by the review team as a whole. A checklist with key words will guide the analysis of each article. The checklist will be developed and refined in consultation with the stakeholders.

Once documents have been screened on the basis of their titles or abstracts, all reasonable effort will be made to obtain the full text electronic or paper copies of the documents. This includes emailing corresponding authors where the full text is not available from web-based sources.

A Kappa analysis [41,42] will be performed on a random sample of 100 titles/abstracts to measure the level of agreement among the four planned reviewers in applying the criteria. If the Kappa score is lower than 0.6, reviewers will discuss the discrepancies and clarify any differences in the interpretation of the inclusion criteria before proceeding. The four reviewers involved in the Kappa process will all have roles in screening the titles, abstracts, and full texts.

\section{Potential effect modifiers and reasons for heterogeneity}

There are many potential effect modifiers such as historical governance approaches and ethnic and linguistic heterogeneity. Drawing from Coleman and Mwangi (2013), potential effect modifiers the reviewers will consider include age of participants, age of resource management group, race, caste, wealth, class, sexual identity, occupation, education level of household head, and high levels of political and economic inequality in a community [43]. These are included in the coding described below.

\section{Study quality assessment}

Assessing a study's quality is complex. There are an estimated 300 existing study quality assessment methods [44], and part of the complexity comes from the large number of potential study designs and the inherent strengths and weaknesses of each design [45]. Bilotta et al. (2014) provides a helpful overview of the study quality assessment and recommends two quality assessment methods for evidence from the environmental sciences [45]. In Bilotta et al. (2014), the recommended GRADE hierarchy of study design is divided into 'randomized controlled trials' and 'observation studies' [46]. This may be problematic for the social sciences where quasi-experimental designs that are neither randomized nor observational are often used, such as propensityscore matching, difference-in-differences, and regression-discontinuity. Some of the studies expected to meet the inclusion criteria of this systematic map are quasi-experimental designs. Thus, we propose to use the environmental Risk of Bias Tool (based on [47]) recommended by Bilotta et al. (2014) in parallel with a widely cited hierarchy of study designs from the social sciences [48]. 
We will use a data extraction template incorporating the methods above to assess a study's quality. A summary explanation for the assigned rating will be included in the data extraction template.

\section{Coding and data extraction strategy}

The data extraction template was designed so that, wherever possible, fixed answers may be selected from coded dropdown lists. The template was tested using documents in the test library and is attached as

Table 3 Draft variables for the data extraction

\begin{tabular}{|c|c|}
\hline Variables & Details/examples \\
\hline ID & Unique ID for each article \\
\hline \multicolumn{2}{|l|}{ Reviewer } \\
\hline \multicolumn{2}{|l|}{ First author } \\
\hline \multicolumn{2}{|l|}{ Year } \\
\hline \multicolumn{2}{|l|}{ Full reference } \\
\hline \multicolumn{2}{|l|}{ URL } \\
\hline Publication type & $\begin{array}{l}\text { E.g., journal, book chapter, conference } \\
\text { paper, thesis, organisation report }\end{array}$ \\
\hline $\begin{array}{l}\text { Article access } \\
\text { issues }\end{array}$ & E.g., none, subscription only, author only \\
\hline Biome & Forest, marine or freshwater \\
\hline \multicolumn{2}{|l|}{ Study country/ies } \\
\hline \multicolumn{2}{|l|}{ Study region(s) } \\
\hline Study length & Time over which study undertaken \\
\hline Study description & Short description of study \\
\hline \multicolumn{2}{|l|}{ Project name } \\
\hline Intervention type & $\begin{array}{l}\text { List of different forest and fish conservation } \\
\text { and resource management interventions }\end{array}$ \\
\hline Primary outcome & Short description of current state \\
\hline $\begin{array}{l}\text { Study design type } \\
\text { and rating }\end{array}$ & $\begin{array}{l}\text { Type of study design and ratings on a } \\
\text { five-point scale as per [48] }\end{array}$ \\
\hline $\begin{array}{l}\text { Method(s) of data } \\
\text { collection }\end{array}$ & List of data collection method(s) \\
\hline Sample size & Number in sample \\
\hline Sample unit & E.g., individuals, households, groups \\
\hline Comparator type & $\begin{array}{l}\text { E.g., randomized } \mathrm{BACl} \text {, non-randomized } \\
\mathrm{BACl} \text {, temporal, spatial, other }\end{array}$ \\
\hline $\begin{array}{l}\text { Other outcome } \\
\text { influences }\end{array}$ & $\begin{array}{l}\text { Mentions a potential effect modifier or a non- } \\
\text { gender inequality the influenced the outcome }\end{array}$ \\
\hline Bias risk type & $\begin{array}{l}\text { Screening for six different types of bias risk as per } \\
\text { [47] }\end{array}$ \\
\hline Bias risk rating & Low, high or unclear \\
\hline $\begin{array}{l}\text { Study quality } \\
\text { rating }\end{array}$ & $\begin{array}{l}\text { Low, high or unclear (combined design and bias } \\
\text { ratings) }\end{array}$ \\
\hline Rating rationale & Summary of the reasons for the rating \\
\hline Additional details & $\begin{array}{l}\text { E.g., multiple outcomes studied, multiple articles in } \\
\text { one source, multiple experiments in one article }\end{array}$ \\
\hline
\end{tabular}

'Additional file 3: Data extraction template and instructions'. From each full-text article included, the draft list of variables in Table 3 will be entered:

The final results from the searches will be added to an Endnote library [35]. Microsoft Excel [49] will be used for the data extraction, and at least two members of the team will test the repeatability of the data extraction and coding.

\section{Study mapping and presentation}

The systematic map outputs will be a narrative report with descriptive statistics to summarize the state of knowledge on the primary research question including the quality of the studies in the review, size of the body of evidence (number of studies found in each sector and geography), consistency of the findings, and a judgement on the external validity of the body of evidence (global, regional, or context-specific). Because influencing policymakers and identifying knowledge gaps are goals of our research, the partner organizations will also produce several Policy Briefs and an 'evidence-gap map' [50] similar to those used by 3ie but populated with primary studies rather than systematic reviews. We will also endeavour to create one or more Theories of Change showing the hypothesized casual pathways of how mixed-gender resource management influences forestry and fisheries resource governance and conservation.

\section{Additional files}

Additional file 1: Articles in the test library.

Additional file 2: Scoping strategy used for bibliographic databases.

Additional file 3: Data extraction template and instructions.

\section{Competing interests}

One co-author (Bina Agarwal) is likely to have articles included in the systematic map, but she will not have a role in the article screening or data extraction.

\section{Authors' contributions}

$\mathrm{CL}, \mathrm{GT}, \mathrm{MD}$ and FB drafted the manuscript and BA, EM, LS, DRo, DRu, TS, and DW provided comments. FB and MD developed the search strategy, with input from $C L$ and GT. CL, MD and FB developed the data extraction strategy. MD and FB will do the title, abstract and full-text screening. CL, GT, MD and FB will do the data extraction. CL will coordinate the review including the analysis and presentation of the results with help from GT, MD, and FB. All authors read and approved the final protocol manuscript.

\section{Acknowledgements}

This review benefited from funding from TNC and the generous support of the American people through USAID under MTO 069018 (Biodiversity Fund) and REQ-EGAT-12-000014 (Measuring Impact) managed by the USAID Office of Forestry and Biodiversity/Bureau for Economic Growth, Education and the Environment. DfID's KnowFor provided funding for the CIFOR contributions. The authors' views expressed in this publication do not necessarily reflect the views of the United States Agency for International Development or the United States Government. 


\section{Author details}

${ }^{1}$ The Nature Conservancy (TNC), 4245 North Fairfax Drive, Arlington, VA 22203, USA. ${ }^{2}$ ICF International (IFCI), 1725 I St NW \#1000, Washington, DC 20006, USA. ${ }^{3}$ International Institute for Environment and Development (IIED), 80-86 Grays Inn Road, London WC1X 8NH, UK. ${ }^{4}$ Center for International Forestry Research (CIFOR), Jalan CIFOR, Situ Gede, Sindang Barang, Bogor 16115, Indonesia. ${ }^{5}$ School of Environment, Education and Development, University of Manchester, Manchester M13 9PL, UK. ${ }^{6}$ Wildlife Conservation Society (WCS), 2300 Southern Blvd, Bronx, NY 10460, USA. ${ }^{7}$ Forestry and Biodiversity Office, United States Agency for International Development (USAID), 1300 Pennsylvania Avenue Northwest, Washington, DC 20004, USA ${ }^{8}$ Conservation Science Partners, 527 Cleveland Street, Missoula, MT 59801, USA.

Received: 10 February 2015 Accepted: 21 April 2015 Published online: 15 June 2015

\section{References}

1. Curtis M, Schmidt C, Struber M. Gender diversity and corporate leadership. Zurich: Credit Suisse; 2012 [http://www.slidesearch.org/slide/gender-diversityandcorporate-performance]

2. Desvaux G, Devillard S, Sancier-Sultan S. Women at the top of corporations: making it happen. Paris: McKinsey and Company; 2010 [http://www.asx. com.au/documents/media/2010 mckinsey_co_women_matter.pdf]

3. Agarwal B. Gender and forest conservation: the impact of women's participation in community forest governance. Ecol Econ. 2009;68:2785-99.

4. Westermann O, Ashby J, Pretty J. Gender and social capital: the importance of gender differences for the maturity and effectiveness of natural resource management groups. World Dev. 2005;33:1783-99.

5. Agarwal B. Gender and green governance: the political economy of women's presence. Oxford: Oxford University Press; 2010.

6. Chattophadhyay R, Duflo E. Women as policy makers: evidence from a randomized policy experiment in India. Econometrica. 2004;72:1409-43.

7. Beaman L, Duflo E, Pande R, Topalova P. Political reservation and substantive representation: evidence from Indian village councils. India Policy Forum. 2010-11;7:159-91.

8. Agarwal B. Does women's proportional strength affect their participation? Governing local forests in South Asia. World Dev. 2010;38:98-112.

9. Sun $Y$, Mwangi E, Meinzen-Dick R. Is gender an important factor influencing user groups' property rights and forestry governance? Empirical analysis from East Africa and Latin America. Int For Rev. 2011;13:205-19.

10. Agarwal B. Bargaining and gender relations: within and beyond the household. Fem Econ. 1997;3:1-51.

11. Gutierrez-Montes I, Emery M, Fernandez-Baca E. Why gender matters to ecological management and poverty reduction. In: Ingram JA, DeClerck F, Rumbaitis Del Rio C, editors. Integrating ecology and poverty reduction. New York: Springer; 2012. p. 39-59.

12. Sunderland T, Achdiawan R, Angelsen A, Babigumira R, Ickowitz A Paumgarten $F$, et al. Challenging perceptions about men, women, and forest product use: a global comparative study. World Dev. 2014;64:S56-66

13. Aguilar L. Framework for conducting gender responsive analysis. Washington DC: IUCN Gender Office; 2014 [http://cmsdata.iucn.org/ downloads/framework_gender_analysis.pdf]

14. Leisher $C$. Kenya's national gender context and its implications for conservation: a gender analysis. Arlington VA: Nature Conservancy; 2013 [http://www.nature.org/science-in-action/leading-with-science/kenyagender-analysis.pdf]

15. Schneider $\mathrm{H}$. The future face of conservation: could it be female? Oryx. 2013:47:1-2.

16. Westerman K. Guidelines for integrating gender into conservation projects. Crystal City, VA: Conservation International; 2014 [http:// peoplefoodandnature.org/blog/demonstrating-how-to-integrate-genderinto-conservation/]

17. Samberg $L$, Leisher $C$. Conservation and gender literature review. The Nature Conservancy: Arlington, VA; 2012.

18. FAO. FRA 2015 terms and definitions. Forest Resources Assessment Working Paper 180. Rome: Food and Agriculture Organization; 2012 [http:// www.fao.org/docrep/017/ap862e/ap862e00.pdf]

19. USAID. Issues in poverty reduction and governance. Washington DC: USAID; 2006 [http://www.usaid.gov/sites/default/files/documents/1862/issues-inpoverty-reduction-and-natural-resource-management.pdf]
20. USAID. User's guide to DRG programming. Washington DC: USAID; 2014 [http://www.usaid.gov/sites/default/files/documents/1866/ DRGUsersGuide_Aug2014.pdf]

21. World Bank. What is Governance? [http://go.worldbank.org/G2CHLXX0Q0]

22. Convention on Biological Diversity. Section 2. Montreal: UN Secretariat of the Convention on Biological Diversity; 1992 [http://www.cbd.int/doc/legal/ cbd-en.pdf]

23. World Economic Forum. 2014 Gender Gap Index. [http://reports.weforum.org/ global-gender-gap-report-2014/rankings/]

24. Pullin AS, Knight TM. Support for decision making in conservation practice: an evidence-based approach. J Nat Con. 2003;11:83-90.

25. Sutherland WJ, Pullin AS, Dolman PM, Knight TM. The need for evidencebased conservation. Trends Ecol Evol. 2004;19:305-8.

26. Pullin AS, Salafsky N. Save the whales? Save the rainforest? Save the data! Conserve Biol. 2010;24:915-7.

27. Spencer L, Ritchie J, Lewis J, Dillon L. Quality in Qualitative Evaluation: A framework for assessing research evidence. Government Chief Social Researcher's Office, London: Cabinet Office; 2003. [http://dera.ioe.ac.uk/ 21069/2/a-quality-framework-tcm6-38740.pdf]

28. Krefting $L$. Rigor in qualitative research: the assessment of trustworthiness. Am J Occup Ther. 1991;45:214-22

29. Cab Abstracts. [http://www.cabi.org/]

30. OvidSP. [http://ovidsp.ovid.com/]

31. Scopus. [http://www.scopus.com/]

32. CAB Thesaurus. [http://www.cabi.org/cabthesaurus/]

33. AGRIS. [http://agris.fao.org/agris-search/index.do]

34. AGRICOLA. [http://agricola.nal.usda.gov/]

35. Endnote. [http://www.endnote.com]

36. Google Scholar. [http://scholar.google.co.uk/]

37. Google. [https://www.google.com/]

38. Poverty and Conservation Learning Group. [http://povertyandconservation.info/]

39. Gender and Environment Working Group. [https://sites.google.com/a/ usaid.gov/gender-environment-working-group/home?pli=1]

40. Hagen-Zanker J, Mallet R. How to do a rigorous, evidence-focused literature review in international development, a guidance note. London: Overseas Development Institute; 2013 [http://www.odi.org.uk/sites/odi.org.uk/files/ odi-assets/publications-opinion-files/8572.pdf]

41. Cohen J. A coefficient of agreement for nominal scales. Educ Psychol Meas. 1960;20:37-46.

42. Edwards P, Clarke M, DiGuiseppi C, Pratap S, Roberts I, Wentz R. Identification of randomized controlled trials in systematic reviews: accuracy and reliability of screening records. Stat Med. 2002;21:1635-40.

43. Coleman EA, Mwangi E. Women's participation in forest management: a cross-country analysis. Global Environ Chang. 2013:23:193-205.

44. Wells K, Littell JH. Study quality assessment in systematic reviews of research on intervention effects. Res Soc Work Pract. 2009;19:52-62.

45. Bilotta GS, Milner AM, Boyd IL. Quality assessment tools for evidence from environmental science. Environ Evid. 2014:3:1-14.

46. GRADE Working Group. Grading quality of evidence and strength of recommendations. Br Med J. 2004;328:1490-4

47. Schünemann HJ, Oxman AD, Vist GE, Higgins JPT, Deeks JJ, Glasziou P, et al. Chapter 12: Interpreting results and drawing conclusions. In: Higgins JPT, Green S, editors. Cochrane Handbook for Systematic Reviews of Interventions Version 5.1.0 (updated March 2011). 2011. [http://www.cochranehandbook.org]

48. Farrington DP, Gottfredson DC, Sherman LW, Welsh BC. The Maryland Scientific Methods Scale. In: Sherman LW, Farrington DP, Welsh BC, MacKenzie DL, editors. Evidence-based crime prevention. London: Routledge; 2002. p. 13-21.

49. Microsoft Excel. [http://office.microsoft.com/en-gb/excel/]

50. Snilstveit B, Vojtkova M, Bhavsar A, Gaarder M. Evidence gap maps-a tool for promoting evidence-informed policy and prioritizing future research. In World Bank Policy Research Working Paper 6725. Washington DC: World Bank; 2013 [http://elibrary.worldbank.org/doi/pdf/10.1596/1813-9450-6725] 